\title{
Chapter 1 Introduction
}

\author{
Alfred Allan
}

The historical roots of professional codes of ethics can be traced back to the Hippocratic Code nearly 2,500 years ago. The first known ethics code for psychologists was adopted by the Consulting Psychologists Association in America in 1933 (Dunbar, 1990 cited by Louw, 1997a). The atrocities committed by Nazi and Japanese health professions during the Second World War and the emergence of psychology as a profession after the War provided impetus to national professional psychological bodies to prepare ethical codes of their own. In Australia, the Australian Branch of the British Psychological Society (BPS) adopted the Code of Professional Ethics (British Psychological Society [Australian Branch], 1949) that was based on a code from Minnesota, in 1949 (Cooke, 2000). At the time, this placed the precursor of the Australian Psychological Society (APS), which was formed in 1944, ahead of other national professional psychological bodies. For example, the American Psychological Association's (APA) first ethics code was published in 1953 and, according to Louw (1997a), this code was adopted with few changes by professional associations in other countries such as South Africa (1955), the Netherlands (1960) and Canada (1962). The BPS only published its ethical principles in 1983.

In the nearly 60 years since 1949 the Australian Code (which at times was called the Code of Professional Conduct) has evolved but retained certain unique features (discussed below) that made it distinctive when compared with other codes. Most of the changes to the Code were made during major reviews in 1960, 1968, 1986 and 1997, but amendments were also made periodically between these reviews.

The first Code of Professional Ethics was a relatively short document with an emphasis on the responsibilities of psychologists to act in the interests of 
their clients, other interested parties, members of the profession, colleagues, and the community. Although the authors of the 1949 Code did not explicitly use the word principle, the Responsibility principle was clearly visible, as was the Nonmaleficence principle, for instance, when the authors reminded psychologists that they were "responsible for a high degree of professional competence" (Cooke, 2000, p. 112). The tone of the document was generally descriptive rather than prescriptive and the term psychologist was consistently used in it.

At the Annual General Meeting in 1956 the members instructed the Executive to "enquire into the working of the Code" (British Psychological Society [Australian Branch], 1960, p. 1). This group for the first time referred to general principles in the 1960 Code of Professional Conduct but the general principles were not clearly articulated. The authors of the 1960 Code also used the word principle, but in the sense that the authors of later codes used the word standard. For instance, principle 13 of section B provided that " $[\mathrm{I}] \mathrm{t}$ is unethical practice to give or receive any form of commission or other remuneration for referral of clients for professional services". Compared to the 1949 Code, provisions regarding research and teaching were more prominent in the 1960 Code. The 1960 Code was a comprehensive document of 35 pages consisting of an introduction, 10 sections of principles, and two appendices. An addendum and a circular explaining the procedures to be followed in cases of complaints or criticism were later added to the 1960 Code. The authors of the 1960 Code used the word psychologist and prescriptive language, which they explained in the following fashion:

The principles contained in this Code are formulated in terms which denote varying degrees of obligation. Members will find that the most vital principles are the most strongly expressed, in terms such as "must", "it is obligatory", etc., indicating that strict observance of such principles is binding on members. (p. 1)

On 21 August 1968 the APS, then a professional body in its own right, adopted a Code of Professional Conduct that was published in the Australian Psychologist two years later (Australian Psychological Society, 1970). The authors of the 1968 Code continued using prescriptive language and replaced the word psychologist with member, except in the general principles section. This Code has the structure that was used until 2007, namely a statement of general principles followed by sections of standards. The 1968 Code had eight sections of standards and also three appendices that, for instance, dealt with issues such as the employment of unqualified persons in psychological practice. It also had an Advice to members section, which contained advice such as:

Members should strive to attain the highest degree of professional competency and integrity in the application of psychological knowledge and techniques. 
In 1976 the Annual General Meeting appointed a working party to inquire into the ethics of psychological practice and research (Cooke, 2000). This working group tried to improve the face validity of the Code by "asking psychologists to give examples of the kinds of things they thought were unethical" (Cooke, 2000, p. 190). The authors of the 1986 Code of Professional Conduct (Australian Psychological Society, 1986) formulated the three general principles that are also found in the 1997 Code of Ethics (Australian Psychological Society, 1997), namely, Responsibility, Competence and Propriety. The 1986 Code further consisted of seven sections of standards and five appendices. Appendix D, for instance, provided guidelines for the ethical use of aversive therapeutic procedures. The word psychologist is consistently used in this Code.

A major reorganization of the APS took place in the mid-nineties and in this process the Code was also reviewed. The new Code was adopted on 4 October 1997 and had the same structure (three general principles and eight sections of standards) and, to a large extent, the same content as the 1986 Code. There were, however, important changes, such as the insertion of standard B.10, which proscribes sexual relationships between psychologists and their former clients for two years. In standard B.11 the authors provided the criteria that would be applied to determine whether sexual relationships between a psychologist and clients that they engage in after two years are unethical. One notable omission from the 1997 Code were the appendices of the 1986 Code, with the exception of the procedure for persons considering involving any section of the Code. Most of the material in the omitted appendices was incorporated in the Guidelines the APS started formulating and eventually published in 1994. In the preface the authors of the 1997 Code referred users to these Guidelines and explained that they were meant to clarify and amplify the application of the principles established in the Code and to facilitate their interpretation. The first collection of the Guidelines was published in 1998. The original version of the 1997 Code used the word psychologist throughout, but it was replaced with the word member on 2 October 1999. This amendment was made in response to a concern expressed at the meeting of the Trans Tasman Council of Psychologist Registration Boards held in Canberra on 28-29 September 1998 regarding the use (and definition) of the word psychologist in the 1997 Code as originally adopted by the APS. This concern stemmed from the fact that the use of the title psychologist is regulated in all the States and Territories.

It is a function of the APS Ethics Committee to reassess regularly the APS Code to ensure that it maintains face validity and remains relevant (Garton, 2004; Sinclair, Poizner, Gilmour-Barrett, \& Randall, 1987) and functional (Louw, 1997a, 1997b). The process of calibration is necessary because of the continued evolution of the APS and changes in community standards, the law, 
and professional structures and practices in Australia and internationally. These routine reassessments led to minor amendments to the 1997 Code in 1999, 2002 and 2003. At its first meeting on 24 November 2004, the 2004-2005 Ethics Committee, however, identified a range of factors that indicated the need for a more comprehensive review of the Code. The most important of these factors will be discussed next.

As the historical overview above demonstrates, a feature of the APS Code had been its evolutionary development which, especially since 1986, had mostly involved piecemeal amendments without a major review. An advantage of this approach was that the Code was familiar to members of the APS and that the standards had face value. As will, nevertheless, be discussed in greater detail by Allan and Symons in Chapter 2, some users of the 1997 Code did note aspects of the Code that were affecting its functionality. There had also been developments in the theory and practice of applied ethics that were not necessarily reflected in the extant Code.

As an organization the APS had also evolved considerably, especially since the mid-nineties, and though the Code was revised at the same time, some of the ramifications of these organizational changes manifested only later and were therefore not considered when the revision took place. Whilst these deliberations were taking place the APS was also embarking on a governance review that led to the restructuring of the Board of Directors and a revising of the functions of the directors.

Nationally, the turn of the century saw important changes to legislation that impacted on professional practice of Australian psychologists, such as the amendments to privacy legislation (Privacy Act, 1988) in 2001. Despite the differences between law and ethics, there is a close relationship between legislation and the content of codes (Tomaszewski, 1979), and codes are a vehicle to educate psychologists about the law. It is therefore essential that ethical codes should be updated regularly to ensure that they reflect the law of the jurisdiction in which they apply.

Whilst the APS Code will always have a national identity because it reflects the law, community attitudes and culture of Australia, the APS must also be cognizant of professional developments at an international level because psychologists across the world face common ethical problems and share common ethical principles (Tomaszewski, 1979). An important development at a geopolitical level in recent times has been globalization, and specifically the closer collaboration of countries at regional levels, as demonstrated by the expansion and consolidation of the European Union and the signing of the North American Free Trade Agreement. One corollary of these accords is that national professional bodies in countries that are signatories are encouraged, if not compelled, to develop common standards. In Europe this had led to the acceptance of a meta-code of ethics by the European Federation of Psycholo- 
gists Associations (EFPA $\left.{ }^{1}, 1995\right)$ at its general assembly in 1995 and the Trilateral Forum on Psychology, Education, Practice, and Credentialing (Bailey, 2004) is working on a meta-code for North America (Edwards, 2000). Australia has likewise entered into a free trade agreement with Singapore (2003), Thailand (2005) the United States of America (2005) and was, at the time the Ethics Committee was considering the review, negotiating such agreements with other countries.

Psychologists themselves have also realized that they should consider identifying and, if necessary, developing international ethical standards. One aspect is that careers are now very portable and working overseas for at least a short period of one's career is more likely to become typical of psychologists in the twenty-first century. Another factor that drives this idea is technological developments, where the Internet and other forms of telecommunication for instance, are changing the way in which psychologists provide services to clients and make it possible for them to provide services across national boundaries (Allan, 2008). An ad hoc joint committee of the International Union of Psychological Science and the International Association of Applied Psychology have therefore commenced formulating a Universal Declaration of Ethical Principles for psychologists (Ad Hoc Joint Committee, 2005; Gauthier, 2004). Meta-codes are unlikely to replace national codes of ethics, but no professional body that is reviewing a code can ignore them.

Members of the Ethics Committee also noted that a number of codes, and in particular the New Zealand Code (New Zealand Psychological Society, 2002) and the Code of the South African Professional Board for Psychology (Professional Board for Psychology, 2002) explicitly referred to the human rights of people. The advantage of doing this is that it would provide the APS and its members with a broader norm system that could guide their ethical decisionmaking in areas not covered by the Code. The importance of having such a broader referral system became apparent during the debate in and around the American Psychological Association's handling of criticism against their members' activities during the Gulf War and after it in military prisons such as the one on Guantanamo Bay (Behnke, 2006; Miles, 2007; Olson, Soldz, \& Davis, 2008).

A set of issues that led to much discussion amongst Ethics Committee members was the relationship between the APS and the Registration Boards ${ }^{2}$,

${ }^{1}$ The body has since been renamed the European Federation of Psychological Associations. The EFPA adopted a revised code in Granada, Spain in 2005 (European Federation of Psychologists Associations, 2005).

${ }^{2}$ At the time of these discussions there were rumours that the registration of health professionals in Australia was about to be reviewed. In December 2005 the Productivity Commission (2005) in its Australia's Health Workplace report recommended the 
the role of the APS and therefore the Ethics Committee, in the regulation of APS members, and the use of the APS Code by Registration Boards, tribunals and courts. The regulation of psychology as a profession consists of three functions, namely the accreditation of training programs, the registration of psychologists and the disciplining of errant psychologists. Whilst the APS has never played a role in the registration of psychologists, it has played a major role in the accreditation of psychological training programs and the disciplining of its members. The APS's influence in both these areas has, however, been eroded since the establishment of the State and Territory Registration Boards (Registrations Boards) starting with Victoria in 1966 (Cooke, 2000).

In the case of accreditation, the establishment of the Australian Branch was in part driven to ensure that psychologists in Australia conformed to high academic standards (Cooke, 2000). In 1972 the APS established two accreditation committees, one for courses leading to associate membership and the other for post-graduate courses leading to full membership. These two committees were later consolidated as the Course Development and Accreditation Committee (CDAC) to decide which courses would be recognized by the APS as sufficient for membership. In subsequent years the Registration Boards have entered the field and this led to the formation of the Australian Psychological Accreditation Council (APAC) in 2003, consisting of representatives of the APS, the Registration Boards and the Heads of Departments and Schools of Psychology Association (HODSPA).

The erosion of the APS's regulatory role can also be seen in the case of the disciplinary function. Until the formation of the Registration Boards, starting in the middle 1960s, the APS's disciplinary functions took place at two levels. At an internal level it governed the interaction between its members to ensure order and solidarity amongst them. This internal disciplinary function of the APS is still intact and is unlikely to change. At an external level the APS acted against members whose negligent or unscrupulous behaviour could harm members of the public and tarnish the public image of the society and psychologists. This external disciplinary role of the APS has to a large extent, but not totally, been taken over by the Registration Boards.

The APS, to start with, retains an external disciplinary role because the National Competition Policy that was implemented in the 1990s requires the

formation of a Registration Board covering all health professions that would take over the accreditation of education programs and the registration and regulation of practitioners at a national level. This was put on the agenda of the Council of Australian Governments (COAG), but in 2007 the proposal was changed to nine separate national boards, including one for psychologists. At the time of writing it appears as if this national registration board will become a reality on 1 July 2010 (Council of Australian Governments [COAG], 2008) and will consist of 10 national boards. 
Registration Boards to primarily focus on the protection of the public and the fostering of professional competition (Crook, 2004). An implication of this narrow focus on the protection of the public is that Registration Boards formulate and enforce minimum standards of conduct for psychologists. Therefore, behaviour that many psychologists would consider to be unacceptable will not incur the sanction of Registration Boards because it does not raise a significant issue of public health or safety. Professional bodies like the APS, in contrast, are obliged to articulate and enforce higher ethical standards for the profession. For example, a Registration Board recently refused to consider a matter where a psychologist had, in a forensic report, commented about the psychological characteristics of a person who the psychologist had not assessed because it ruled that the behaviour did not raise a significant issue of public health or safety. This decision may be correct from the perspective of a Registration Board; however, this is behaviour many psychologists will consider to be unethical and is proscribed in principle $\mathrm{VI}(\mathrm{H})$ of the speciality guidelines for forensic psychologists of the American Psychology-Law Society (Committee on Ethical Guidelines for Forensic Psychologists, 1991) and clause 7.3 of the South African Code (Professional Board for Psychology, 2002).

The Ethics Committee must, furthermore, discipline members whose negligent or unscrupulous behaviour could harm members of the public and tarnish its public image or that of psychologists, even though the matter may already have been dealt with by the relevant Registration Board. There are three reasons for this. Firstly, no professional organization can be perceived to condone the behaviour of a member who is seen as a danger to the public. The APS, secondly, provides a referral service to members of the public seeking the services of a psychologist and it could be argued that by providing the names of members to potential clients the APS implicitly represents the members as competent and ethical practitioners. There is therefore a high likelihood that referred clients who believe that they may have been wrongfully harmed by members could sue the APS. The APS must therefore have a system of monitoring and regulating the professional behaviour of its members. The APS, thirdly, uses its group purchasing power to negotiate group professional indemnity insurance for participating members. As the premiums members pay are influenced by the insurance claims made against members, it is important for the APS and its members to ensure that the professional behaviour of all members is of such a standard that it will not attract claims from aggrieved clients.

Nevertheless, the disciplining of psychologists is the primary responsibility of the Registration Boards and therefore the Council of Psychologist Registration Boards (CPRB) and the APS have agreed that the Ethics Committee will refer all complaints against members to the applicable Registration Board, with the exceptions of complaints by members against each other that do not 
involve the public. When they refer complainants to Registration Boards, the APS invites them to resubmit complaints to the APS once they have been dealt with by the relevant Registration Board or if it refuses to deal with the matter. The Registration Boards also occasionally refer matters to the APS out of their own accord.

Despite the decline of the APS's role as a disciplinary body, its Code has maintained a prominent position and is seen by the Registration Boards and Courts (Psychologist Registration Board $v$ Robinson, 2004) as the primary indicator of acceptable professional conduct among Australian psychologists. It is also very likely that civil courts may, if they have not yet done so, use the APS Code to determine the standard of conduct that is expected of psychologists. The Ethics Committee welcomed this general acceptance of the APS Code because it is clearly not in the interest of the profession to have a proliferation of ethical codes for psychologists which are expensive to draft and could lead to disparate, or apparently disparate, standards. This may confuse both psychologists and members of the public. The Ethics Committee further noted that the legislation in some states and territories currently requires some Registration Boards to refer serious disciplinary matters to administrative tribunals where they will be adjudicated by lawyers. This has two important implications. To start with, the experience in Canada demonstrated that a code will maintain its status as a regulatory document in such a forum only if its provisions are enforceable (Dobson \& Breault, 1998). Furthermore, the code must make a clear distinction between enforceable minimum behavioural standards and aspirational standards on the one hand, and practice guidelines on the other hand.

After considering all these factors, the Ethics Committee decided on 21 January 2005 to recommend to the Board of Directors that the Code should be reviewed. In response the Board of Directors appointed a Code Review Working Group (Group) in April 2005 which engaged in a process of research, in-depth deliberation, and consultations with members, other stakeholders and other knowledgeable people that are described more fully by Allan and Symons in Chapter 2. The first face-to-face meeting of the Group was a roundtable discussion on 16 and 17 February 2006 and many of the chapters in this book evolved from working papers presented on this occasion.

A glimpse of the research that preceded the review of the 1997 Code can be found in Chapter 3, where Alfred Allan firstly recorded the material he presented at the roundtable in which he explored the function of codes of ethics and the functionality of the 1997 Code. In the latter part of the chapter he indicates how the Group in response tried to improve the functionality of the 2007 Code. Chapter 4 by William Warren is also based on material he presented at the roundtable in which he critically and provocatively examined the multiplicity of codes that regulate the behaviour of psychologists and questioned 
whether a comprehensive review of the 1997 Code was required. In Chapter 4 he examines how the Group tried to address some of the matters he raised in his presentation and also reflects on some of the philosophical issues that emerged during the deliberations of the Group.

A major stakeholder that was directly involved in the review process was the CPRB; its representative, David Collier, is therefore ideally suited to comment on the review process as an observer. He does this in Chapter 5 and also provides a broader perspective on the work of the Group and the 2007 Code.

The Group decided at its round table meeting that it would use a principle approach in drafting the 2007 Code and in Chapter 6 Alfred Allan discusses the principles that underlie the Code and explains how these principles were identified. In the next chapter Graham Davidson, Alfred Allan and Anthony Love discuss the practical implications of some of these principles with reference to issues of consent, privacy and confidentiality. In Chapter 8 Anthony Love considers how educators can use this explicit framework of the 2007 Code to teach trainee psychologists and practising psychologists about ethics. He also considers the role that the Code can play in educators' replanning of ethics education for psychology students and make suggestions for improving ongoing professional development of psychologists.

Another explicit goal of the Group was to bring a greater emphasis on social psychology into the Code and in Chapter 9 Graham Davidson reflects on the efforts the Group undertook to do this and the obstacles it encountered and explains the social impact of the provisions of the 2007 Code.

The Group's deliberate decision to exclude practical guidelines from the 2007 Code meant that there are no specific provisions in it regarding, for instance, working with older and younger people. The 2007 Code, however, provides ample guidance to psychologists working with these populations as Marie Joyce demonstrates in Chapter 10, where she considers some core ethical issues for psychologists working with children, in particular informed consent and confidentiality, with reference to United Nations' Convention on the Rights of the Child. Marie also considers the inherent limitation of the principled approach used by the Group by examining the virtue ethics approach of the philosopher Emmanuel Levinas.

In Chapter 11 Sabine Hammond considers the important issues of management of boundaries and multiple relationships. Complaints about inappropriate mixing of roles, conflict of interest and boundary violations accounted for a high percentage of complaints received by Registration Boards and these issues evoked many vigorous debates amongst the members of the Group. As this was particularly true in respect of the sexual activities by psychologists in relation to their clients and former clients, Alfred Allan and Donald Thomson discuss and explain the relevant standards in the 2007 Code in greater detail 
in Chapter 12. In the final chapter of the book, Anthony Love and Alfred Allan consider the ethical challenges that face the profession in the foreseeable future.

The purpose of the authors of this book was primarily to share the insights they gained during the review process, record the issues they grappled with during the process and, in some cases, critically consider some of the standards in the 2007 Code. As such, the book provides valuable insights in the review process of a code of ethics, the problems that confront people who undertake such a task and is also a valuable source of data about professional ethics. The authors trust that the book will encourage readers to become immersed in the issues that are covered so they are informed and can contribute to the ongoing evolution of the APS's Code of Ethics.

\section{References}

Allan, A. (2008). An international perspective of law and ethics in psychology. Somerset West, South Africa: Inter-ed.

Ad Hoc Joint Committee. (2005). Draft: Universal declaration of ethical principles of psychologists. Unpublished manuscript.

Australian Psychological Society. (1970). Code of professional conduct and advice to members. Australian Psychologist, 5, 75-95.

Australian Psychological Society. (1986). Code of professional conduct. Melbourne, Australia.

Australian Psychological Society. (1997). Code of ethics. Melbourne, Australia: Author.

Bailey, D. S. (2004). Beyond our borders. Monitor on Psychology, 35, 58.

Behnke, S. (2006). Ethics and interrogations: Comparing and contrasting the American Psychological, American Medical and American Psychiatric Association positions. Monitor on Psychology, 37, 6.

British Psychological Society [Australian Branch]. (1949). Code of professional ethics.

British Psychological Society [Australian Branch]. (1960). Code of professional conduct.

Committee on Ethical Guidelines for Forensic Psychologists. (1991). Speciality guidelines for forensic psychologists. Law and Human Behavior, 15, 655-65.

Cooke, J. S. (2000). A meeting of minds: The Australian Psychological Society and Australian psychologists 1944-1994. Melbourne: Australian Psychological Society.

Council of Australian Governments (COAG). (2008). Comminiqué [Electronic Version]. Retrieved 26 March 2008 from www.coag.gov.au/meetings/260308/ index.htm\#health.

Crook, A. (2004). Movement on acts: Psychologist and the state psychologists registration boards. InPsych, 10-11.

Dobson, K. S., \& Breault, L. (1998). The Canadian Code of ethics and the regulation of psychology. Canadian Psychology, 39, 212-18. 
Edwards, H. P. (2000). Trilateral forum on professional psychology working notes of the year 2000 meeting [Electronic Version]. Retrieved 2 December 2005 from www. fitpsy.org/cached/trilateral/trilat2000.pdf.

European Federation of Professional Psychologists Associations (EFPA). (1995). Meta-code of ethics. Retrieved from 12 February 2000 from www.cop.es/efppa/ metacode.htm.

European Federation of Psychologists Associations. (2005). Meta-code of ethics. Retrieved 12 February 2006 from www.efpa.be/ethics.php.

Garton, A. F. (2004). Psychology in Australia. In M. J. Stevens \& D. Wedding (Eds.), Handbook of international psychology (pp. 437-52). New York: Brunner-Routledge.

Gauthier, J. (2004). Toward a universal declaration of ethical principles of psychologists: A progress report. Retrieved 10 May 2007 from www.am.org/iupsys/ethprog1.pdf.

Louw, J. (1997a). Regulating professional conduct Part I: Codes of ethics of national psychology associations in South Africa. South African Journal of Psychology, 27, 183-8.

Louw, J. (1997b). Regulating professional conduct Part II: The Professional Board for Psychology in South Africa. South African Journal of Psychology, 27, 189-95.

Miles, S. (2007). Medical ethics and the interrogation of Guantanamo 063. The American Journal of Bioethics, 7, W3.

New Zealand Psychological Society. (2002). Code of ethics. Retrieved 17 September 2003 from www.psychology.org.nz/.

Olson, B., Soldz, S., \& Davis, M. (2008). The ethics of interrogation and the American Psychological Association: A critique of policy and process. Philosophy, Ethics, and Humanities in Medicine, 3.

Privacy Act 119 of 1988. (Commonwealth).

Productivity Commission. (2005). Australia's health workforce: Research report [Electronic Version]. Retrieved 19 January 2006 from www.pc.gov.au/study/ healthworkforce/docs/finalreport.

Professional Board for Psychology. (2002). Ethical code of professional conduct. Retrieved 17 September 2003 from www.psyssa.com/aboutus/codeofconduct.asp.

Psychologist Registration Board v Robinson. (2004). QCA 405.

Sinclair, C., Poizner, S., Gilmour-Barrett, K., \& Randall, D. (1987). The development of a code of ethics for Canadian psychologists. Canadian Psychology, 28, 1-11.

Tomaszewski, T. (1979). Ethical issues from an international perspective. International Journal of Psychology, 14, 131-5. 
